\title{
Implicit Attitudes of Chinese University Students towards Altruism: Evidence from Single Category Implicit Association Test
}

\author{
Rui Wu, Qingke Guo* \\ Department of Psychology, Shandong Normal University, Jinan, China \\ Email: "guoqingke@163.com
}

Received 12 February 2016; accepted 27 June 2016; published 30 June 2016

Copyright (C) 2016 by authors and Scientific Research Publishing Inc.

This work is licensed under the Creative Commons Attribution International License (CC BY).

http://creativecommons.org/licenses/by/4.0/

(c) (i) Open Access

\begin{abstract}
IAT measures are supposed to be able to remove the effects that come from people's natural tendency to believe that they have socially desirable traits. In the present study, the Single Category Implicit Association Test (SC-IAT) was used to explore implicit attitudes and self-images of Chinese university students with respect to altruism. Three kinds of altruism (general altruism, kin altruism and reciprocal altruism) were considered to detect the participants' implicit attitudes and self-images. Specific wording was incorporated in the SC-IAT measures to explore whether the students believed that apparent altruism in others was honest or hypocritical. The results show: 1) Chinese students generally hold positive implicit attitudes towards kin, reciprocal, and general altruism, but the positive attitudes towards reciprocal and kin altruism are significantly stronger than towards general altruism. 2) Chinese students regard themselves neither as altruistic nor selfish in their implicit self-concepts. 3) Chinese students tend to judge altruism as honest rather than hypocritical behavior, especially in the cases of kin and reciprocal altruism.
\end{abstract}

\section{Keywords}

SC-IAT, Implicit Altruistic Attitude, Implicit Altruistic Self-Concept

\section{Introduction}

\subsection{Implicit Association Test}

The Implicit Association Test (Greenwald, McGhee, \& Schwartz, 1998) has been widely used in many attitude

${ }^{*}$ Corresponding author.

How to cite this paper: Wu, R. and Guo, Q.K. (2016). Implicit Attitudes of Chinese University Students towards Altruism: Evidence from Single Category Implicit Association Test. Psychology, 7, 965-975.

http://dx.doi.org/10.4236/psych.2016.77097 
and personality domains due to its supposed ability to avoid responses colored by people's natural desire to believe that they have socially desirable traits. The IAT is flexible and easy to implement, and it shows special value in measuring sensitive topics (Popa-Roch \& Delmas, 2010; van Ravenzwaaij, van der Maas, \& Wagenmakers, 2011). On many occasions, IAT measures show satisfactory reliability (Bar-Anan \& Nosek, 2013; Banse \& Greenwald, 2007) and considerable validity in predicting overt behaviors (Greenwald, Poehlman, Uhlmann, \& Banaji, 2009; Lindgren, Neighbors, Teachman, \& Wiers, 2013; Rudolph, Schröder-Abé, Riketta, \& Schütz, 2010).

\subsection{SC-IAT}

While Classical IAT has been considered as a relative measure of attitudes, its validity was handicapped by the problems of recoding (Fiedler, Messner, \& Bluemke, 2006; Fleischhauer, Strobel, Enge, \& Strobel, 2013; Gast \& Rothermund, 2010; Karpinski \& Hilton, 2001). To overcome these shortcomings, new implicit measures had have been proposed. The Single Category Implicit Association Test (SC-IAT) is a good example (Karpinski \& Steinman, 2006).

SC-IAT is designed to assess the implicit attitude towards a single target concept. As Karpinski \& Steinman (2006) suggested, the SC-IAT can assess the absolute attitude, and its administration and data analysis procedure is more concise but effective than the IAT. SC-IAT's reliability, validity and the ability to control conscious participation have been considered satisfactory (Karpinski \& Steinman, 2006; Cuyper, Pieters, Claes, Vandromme, \& Hermans, 2013; Rudolph, Schröder-Abé, Schütz, Gregg, \& Sedikides, 2008; Tian, Liu, \& Gilman, 2010). For instance, Karpinski \& Steinman (2006) designed SC-IAT measures to assess implicit attitudes towards sodas, self-esteem and race. They found: 1) the reliability of the SC-IAT is similar to or higher than the IAT; 2) the explicit measure of self-esteem correlates with SC-IAT but not IAT; 3) conscious participation could be controlled more successfully in SC-IAT than in IAT. In a study led by Cuyper \& colleges (2013), implicit perfectionism (automatically self-evaluated achievement striving) assessed by SC-IAT correlated significantly with explicit perfectionism and verified the power of SC-IAT in predicting explicit behaviors.

\subsection{Implicit Attitude Measures and Overt Behavior}

Implicit measures have proved to be good predictors of automatic behaviors (Rudolph et al., 2010; Fleischhauer et al., 2013; Aspden, Ingledew, \& Parkinson, 2012; Perugini, Conner, \& O’Gorman, 2011). Their incremental validity over explicit measures has also been verified (Cuyper et al., 2013).

Perugini, Conner, \& O’Gorman (2011) designed the implicit altruistic attitude IAT and implicit altruistic self-concept IAT to predict altruistic behavior. They found: 1) The IAT measures correlated significantly with spontaneous helping behavior instead of general volunteering; self-reported altruism measures significantly correlated only with general volunteering, indicating that the explicit measure and the implicit measure predict different behavior. 2) IAT measures correlated significantly with monthly specific volunteering, while the selfreported helpfulness scale correlated significantly with general volunteering and monthly specific volunteering, indicating that there are behaviors that can be predicted by both the explicit and the implicit measures.

These studies revealed that behaviors can be predicted by people's attitudes. Whether the prediction occurs at the explicit or implicit level depends on what kind of behaviors is to be predicted. On considering this, we adopt implicit altruism measures to explore Chinese people's true attitudes towards altruism through which the characteristic of their altruistic behavior are expected to be explored.

\subsection{Altruistic Behavior}

Altruistic behavior refers to the helping behaviors that benefit others at a cost to the actor (Barclay, 2013). In this study we considered three kinds of altruism: kin altruism, reciprocal altruism and general altruism. Human are more likely to help those with whom they share a lot of genes. This kind of helping behaviors is called kin altruism which can be interpreted as the extension of self interest of the helper (Hamilton, 1964). Due to shared genes, helping kin can increase the reproductive fitness of the actor though maybe a cost at present. Large amounts of studies had verified Hamilton's rule in both human and animal world (Krupp, DeBruine, \& Barclay, 2008). Reciprocal altruism was the expansion of kin altruism (Trivers, 1971). Reciprocity is important for harmonious relationships in small group even relatives (Fletcher \& Zwick, 2006; Queller, 1985). 
Through socialization most human individuals have to extend their social relationships beyond kin. If altruists can obtain subsequent reciprocation in a certain form, their current loss of fitness can be compensated in the future. General altruism refers to the altruistic behavior carried out on all humans (especially strangers, but kin and allies are not ruled out). It is used here as the synonym of "true altruism" or classical "altruism". Compassion may be an important reason for general altruism because kin selection and reciprocal altruism do not fully explain why individuals help strangers in anonymous contexts.

\subsection{The Present Study}

Altruism is a hot topic in Chinese academia and public. However, the current situation of charitable donation in China is not satisfying. According to Charities Aid Foundation's report (CAF) (retrieved November 5, 2014, from https://www.cafonline.org/PDF/WorldGivingIndex2013 1374AWEB.pdf), Mainland China ranked 133 among all 135 countries in World Giving Index. In the face of this reality, it is reasonable for us to suspect the humanity of Chinese people. In the present study SC-IAT was used to explore Chinese people's implicit attitudes towards altruism. Taking into consideration the nature of Chinese culture, three kinds of altruism (i.e. kin altruism, reciprocal altruism, and general altruism) were discerned and measured respectively.

Human altruistic behavior is the co-evolutionary product of gene and culture. Chinese people's implicit attitudes towards altruism embody the common human nature developed through human's evolutionary history. In the meantime, culture norm to which Chinese people conform also models the formulation and presentation of their implicit attitudes towards altruism. Based on this logic, we articulated three hypotheses listed below:

Hypothesis 1: Chinese participants' implicit attitudes towards altruism are generally positive; their implicit self-concepts are altruistic, and they tended to use altruistic words to describe themselves rather than others.

Hypothesis 2: As the nurtured results of traditional cultural values, the intensity of Chinese people's implicit attitudes towards kin, reciprocal and general altruism are different.

Hypothesis 3: Confucius and Mencius strongly advocated priority of kin altruism over general altruism (Nichols, 2013). Influenced by such ideology, Chinese may regard general altruism as hypocritical. So we presumed that the participants' implicit attitudes towards kin altruism and reciprocal altruism be labeled as honest, but it may not be the case for general altruism.

\section{Method}

\subsection{Participants}

One hundred and ninety-nine university students were recruited as participants and twelve were deleted because of incomplete responses. In the valid sample 89 students (12 males, 77 females) participated in the implicit altruistic self-concept SC-IAT and 98 students (22 males, 76 females) participated in the implicit altruistic attitude SC-IAT. They were presented delicate gifts for participation.

\subsection{Ethics Statement}

The study was approved by the Institutional Review Board (IRB) of Shandong Normal University. The tests caused no harm to participants' physical or mental health, and the results of this study were maintained confidentially. All participants were over 18 years old and there were no minors or children involved in the study. Evidence showed that all participants were provided with written informed consent as approved by the ethics committee.

\subsection{Materials and Procedure}

SC-IAT measures (see Appendix A) designed to test the implicit altruistic attitudes and self-concepts were administrated to two participant groups respectively. The administration order of three kinds of altruism was balanced by a Latin square design in order to counteract sequential effect. Four neutral words (see Appendix B) were added into the implicit attitude SC-IAT measures to balance participants' responding. All participants were tested individually in a quiet laboratory.

In kin altruistic attitude SC-IAT measure, 6 words representing kin Altruism were used as target words (see Appendix B), while the attribute words were 10 commendatory terms (including 5 words representing honest 
traits), 10 derogatory terms (including 5 words representing hypocritical traits) and 4 neutral words (see Appendix B). There were two stages when administrating SC-IAT measures and each stage consists of 30 practice trials which were immediately followed by 72 test trials. In the first stage (kin altruism, positive), kin altruism words and positive words were categorized on the F key, negative words were categorized on the J key, and neutral words were categorized on the space key. In an attempt to prevent response bias, kin altruism words, positive words, negative words, and neutral words were presented in a ratio of $18: 24: 22: 8$, so $58 \%$ of correct responses were on the F key and 31\% of correct responses were on the J key. In the second stage (kin altruism, negative), positive words were categorized on the $\mathrm{J}$ key, kin altruism words and negative words were categorized on the F key, neutral words were categorized on the space key.

Each stage was preceded by a set of instructions concerning the categorization task and the appropriate responses. Each word appeared on the center of screen for a time limit of $1500 \mathrm{~ms}$. When the participants failed to respond, a reminder as "Please respond more quickly!" appeared for $500 \mathrm{~ms}$. In this procedure a sense of urgency was created to decrease conscious participation. Participants were given feedback regarding the accuracy of their response to each task: A green " $\sqrt{ }$ " appeared on the center of the screen for $150 \mathrm{~ms}$ after each correct response and a red " $x$ " appeared on the center of the screen for $150 \mathrm{~ms}$ after each incorrect response. The administration of reciprocal and general altruistic attitude SC-IAT measures was similar to the above procedure, with the only difference of target words.

For the kin, reciprocal, and general altruistic self-concept SC-IAT measures, the attribute words were self (I, me, my, we, us, our) and other (he, his, she, her, they, their), whereas the target words were the same as those in the corresponding attitudes SC-IAT measures. The testing procedures of the three altruistic self-concept SC-IAT measures were similar to those of altruistic attitude SC-IAT. All words were presented in Chinese. Their English counterparts were listed in Appendix B.

The repetitive measurement deviation analysis was used to analyze the data via spss16.

\section{Results}

\subsection{Reliability and D Value}

After deleting invalid data, in the implicit altruistic self-concept SC-IAT, 89 students' (12 males, 77 females, mean age was 21.2, standard deviation was 2.01) data were analyzed, and in the implicit altruistic attitude SC-IAT, 98 students' (22 males, 76 females, mean age was 20.7, standard deviation was 2.45) data were analyzed. We adopted the method proposed by Karpinski \& Steinman (2006) when analyzing test data. Nonresponse and responses with lengths less than $350 \mathrm{~ms}$ were eliminated, and incorrect responses were replaced with the block mean plus an error penalty of $400 \mathrm{~ms}$. Then we separated 60 compatible and 60 incompatible trials in each SC-IAT into three parts and calculated a SC-IAT score separately for each of the trials without dividing by the standard deviation of RT (response time) of correct response. The internal consistency was obtained by calculating the average inter-correlation among the three scores. Then the Spearman-Brown formula was adopted for correction. To calculate D-value, the average RT of compatible tasks was subtracted from the average RT of incompatible tasks. This quantity was divided by the standard deviation of RT of all correct response within compatible and incompatible tasks. The results were listed in Table 1.

\subsection{Implicit Altruistic Attitudes}

The scores of altruistic attitudes SC-IAT measures were analyzed using a 3 (altruism type: general altruism, reciprocal altruism, kin altruism) $\times 2$ (task type: compatible task, incompatible task) ANOVA with repeated measures on both variables. Mean RT and SD were listed in Table 2.

The results showed (also demonstrated as Figure 1):

1) The main effect of altruism type was significant $\left(F(2,194)=24.90, p<0.001\right.$, partial $\left.\eta^{2}=0.20\right)$. Post hoc comparisons (least significant difference, LSD) revealed that the mean RT of general altruism was significantly longer than those of reciprocal and kin altruism (ps $<0.001$ ), and the mean RT of reciprocal altruism and kin altruism showed no difference $(p>0.05)$.

$2)$ The main effect of task type was significant $\left(F(1,97)=229.19, p<0.001\right.$, partial $\left.\eta^{2}=0.70\right)$. The mean RT scores of incompatible tasks were significantly longer than those of compatible tasks, meaning that participants' responses were slower in incompatible tasks than in compatible tasks. 
Table 1. Reliability coefficients and D-values of 12 implicit tests.

\begin{tabular}{ccccc}
\hline & \multicolumn{2}{c}{ Altruistic self-concept SC-IAT } & \multicolumn{2}{c}{ Altruistic attitude SC-IAT } \\
\hline & reliability & D-value & reliability & D-value \\
\hline General altruism & 0.42 & 0.01 & 0.68 & 0.58 \\
Reciprocal altruism & 0.79 & 0.05 & 0.74 & 0.58 \\
Kin altruism & 0.41 & 0.01 & 0.86 & 0.47 \\
\hline
\end{tabular}

Table 2. Mean RT scores and SD of 12 implicit tests.

\begin{tabular}{ccccc}
\hline & \multicolumn{2}{c}{ Altruistic attitude SC-IAT } & \multicolumn{2}{c}{ Altruistic self-concept SC-IAT } \\
\cline { 2 - 5 } & Compatible task & Incompatible task & Compatible task & Incompatible task \\
\hline \multirow{2}{*}{ General altruism } & 626.81 & 796.64 & 681.56 & 683.26 \\
& 9.90 & 17.99 & 11.21 & 10.71 \\
Reciprocal altruism & 577.12 & 726.12 & 599.36 & 608.06 \\
& 8.47 & 13.86 & 10.24 & 5.04 \\
Kin altruism & 584.03 & 712.77 & 556.80 & 860.09 \\
\hline
\end{tabular}

Note: Mean RT and SD were respectively displayed in the first and second row of each kind of altruism.

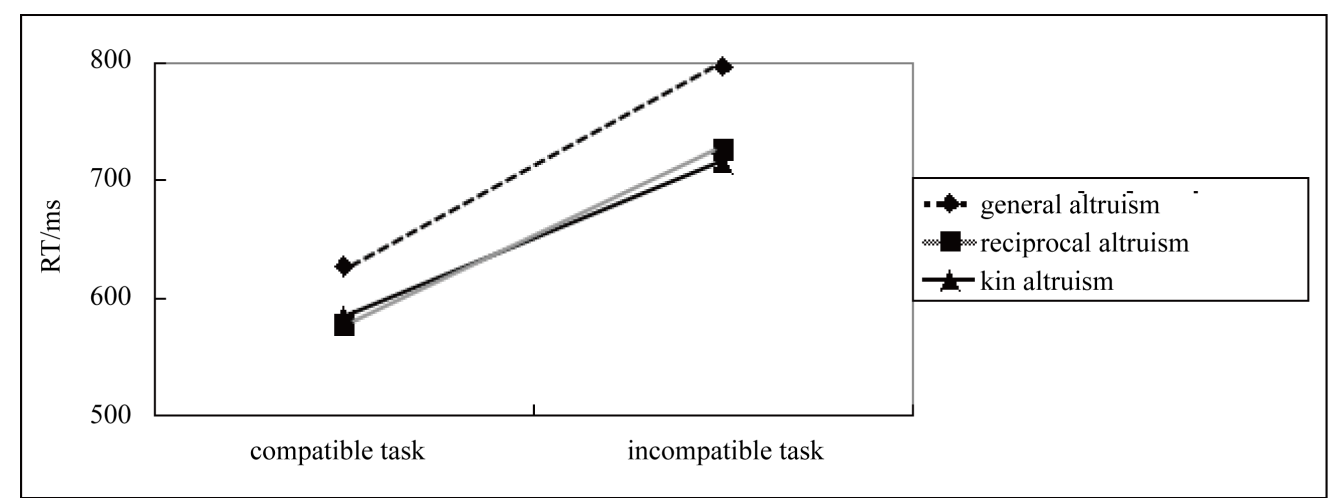

Figure 1. RT scores of implicit altruistic attitude SC-IAT measures.

3) The interaction between altruism type and task type was not significant $(\mathrm{F}(2,194)=3.03, p>0.05$, partial $\eta^{2}=0.03$ ), suggesting that participants' responses were slower in incompatible tasks than in compatible tasks for all three kinds of altruism.

\subsection{Implicit Altruistic Self-Concepts}

Altruistic self-concepts measured by SC-IAT were analyzed using a 3 (altruism types: general altruism, reciprocal altruism, kin altruism) $\times 2$ (task types: compatible task, incompatible task) ANOVA with repeated measures on both variables. Mean RT and SD were demonstrated in Table 2. The results showed (also demonstrated as Figure 2):

1) The main effect of altruism type was significant $\left(F(2,176)=154.60, p<0.001\right.$, partial $\left.\eta^{2}=0.64\right)$. Post hoc comparisons (LSD) revealed that the mean RT of general altruism was significantly longer than those of reciprocal and kin altruism (ps $<0.001$ ), and the mean RT of reciprocal altruism was significantly longer than that of kin altruism $(p<0.001)$.

2) The main effect of task type was not significant $\left(F(1,88)=0.46, p>0.05\right.$, partial $\left.\eta^{2}=0.005\right)$. 


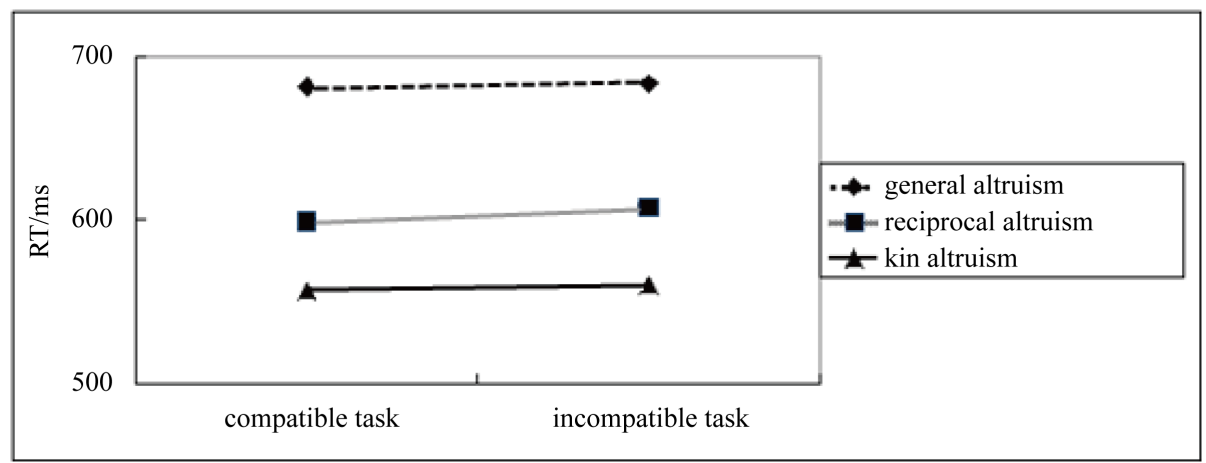

Figure 2. RT scores of altruistic self-concept SC-IAT measures.

3) The interaction between altruism type and task type was not significant $(\mathrm{F}(2,176)=0.30, p>0.05$, partial $\left.\eta^{2}=0.003\right)$.

\subsection{Implicit Honest/Hypocritical Attitudes towards Altruism}

In altruistic attitude SC-IAT measures, participants' responses to honest/hypocritical, altruistic/selfish words were selected for a separate analysis. After a 3 (altruism types: general altruism, reciprocal altruism, kin altruism) $\times 2$ (attitude type: honest/hypocritical attitude, general positive/negative attitude) $\times 2$ (task type: compatible task, incompatible task) ANOVA with repeated measures on the three variables, mean RT and SD were demonstrated in Table 3.

The results showed that:

1) The main effect of altruism type was significant $\left(F(2,194)=25.63, p<0.001\right.$, partial $\left.\eta^{2}=0.21\right)$. Post hoc comparisons (LSD) revealed that the mean RT of general altruism was significantly longer than those of reciprocal and kin altruism (ps < 0.001) (with no significant difference between the latter two).

2) The main effect of attitude type was significant $\left(F(1,97)=18.63, p<0.001\right.$, partial $\left.\eta^{2}=0.16\right)$. Participants' responses to honest/hypocritical words were significantly longer than responses to general positive/negative words. In other words, participants' responses to honest/hypocritical words were slower than to general positive/negative words.

3) The main effect of task type was significant $\left(F(1,97)=212.86, p<0.001\right.$, partial $\left.\eta^{2}=0.69\right)$, with longer mean RT scores in incompatible tasks significantly than that in compatible tasks.

4) The interaction between altruism type and attitude type was significant $(\mathrm{F}(2,194)=8.32, p<0.001$, partial $\eta^{2}=0.08$, also shown in Figure 3). Simple effect analysis suggested that, there was significant variance among three kinds of altruism (ps < 0.001) at each levels of attitude type. Post hoc comparison revealed that, for honest/hypocritical words, participants' responses to general altruism words were slower than the responses to kin and reciprocal words (ps < 0.001) with no significant variance between the other two. Similarly, for general positive/negative words, participants' responses to general altruism were slower than the responses to kin and reciprocal words ( $\mathrm{ps}<0.001$ ) with no significant variance between the latter two.

5) The interaction between altruism type and task type was not significant $(\mathrm{F}(2,194)=2.17, p>0.05$, partial $\eta^{2}=0.02$, see Figure 4), suggesting that participants' responses were slower in incompatible tasks than those in compatible tasks for all three kinds of altruism.

6) The interaction between attitude type and task type was not significant $\left(F(1,97)=0.09, p>0.05\right.$, partial $\eta^{2}$ $=0.001$ ), showing that participants' responses were slower in incompatible tasks than that in compatible tasks either for honest/hypocritical words or for general positive/negative words for three kinds of altruism.

7) The interaction among altruism type, attitude type, and task type were not significant $(\mathrm{F}(2,194)=0.37$, $p>0.05$, partial $\eta^{2}=0.004$ ).

\section{General Discussion}

\subsection{Reliability and D-Values}

The reliability coefficients for the three implicit altruistic attitude SC-IAT measures range from 0.68 - 0.86, and 
Table 3. Mean RT and SD of honest/hypocritical attitude SC-IAT measures.

\begin{tabular}{cccccccccc}
\hline & \multicolumn{2}{c}{ Compatible task } & \multicolumn{2}{c}{ Incompatible task } & \multicolumn{2}{c}{ Honest/hypocritical } & \multicolumn{2}{c}{ Ordinary positive/negative } \\
\cline { 2 - 9 } & $\mathrm{RT}$ & $\mathrm{SD}$ & $\mathrm{RT}$ & $\mathrm{SD}$ & $\mathrm{RT}$ & $\mathrm{SD}$ & $\mathrm{RT}$ & $\mathrm{SD}$ \\
\hline $\begin{array}{c}\text { General altruism } \\
\begin{array}{c}\text { Reciprocal } \\
\text { altruism }\end{array}\end{array}$ & 620.89 & 9.75 & 764.11 & 16.62 & 691.80 & 11.68 & 693.21 & 11.55 \\
$\begin{array}{c}\text { Kin altruism } \\
\text { Kin }\end{array}$ & 571.90 & 8.41 & 709.00 & 13.52 & 647.63 & 10.47 & 633.26 & 10.09 \\
\hline
\end{tabular}

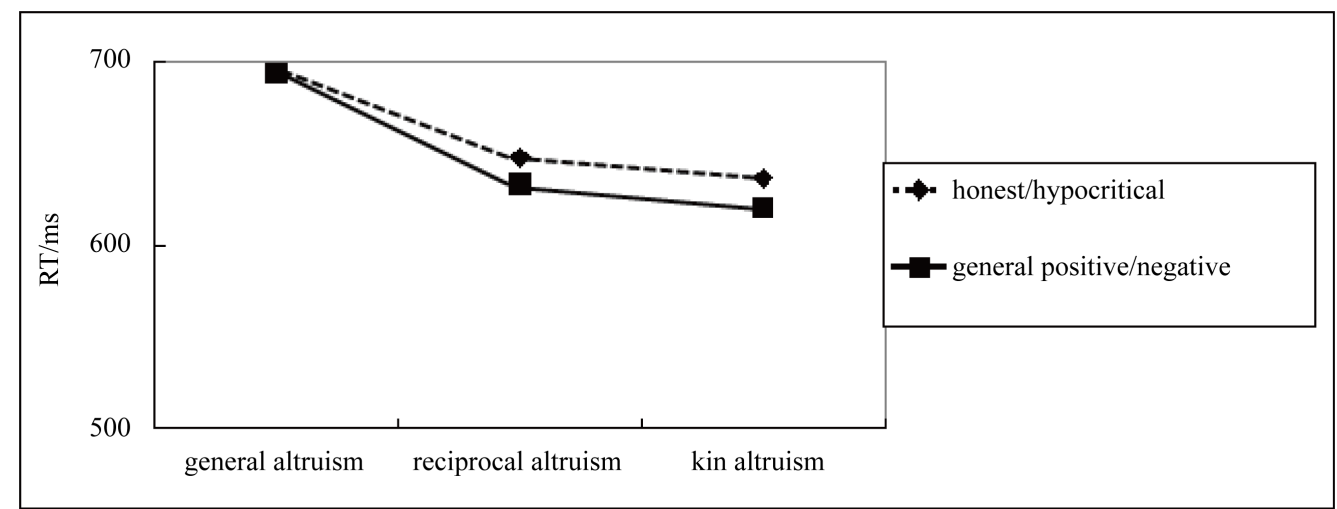

Figure 3. The interaction between altruism type and attitude type.

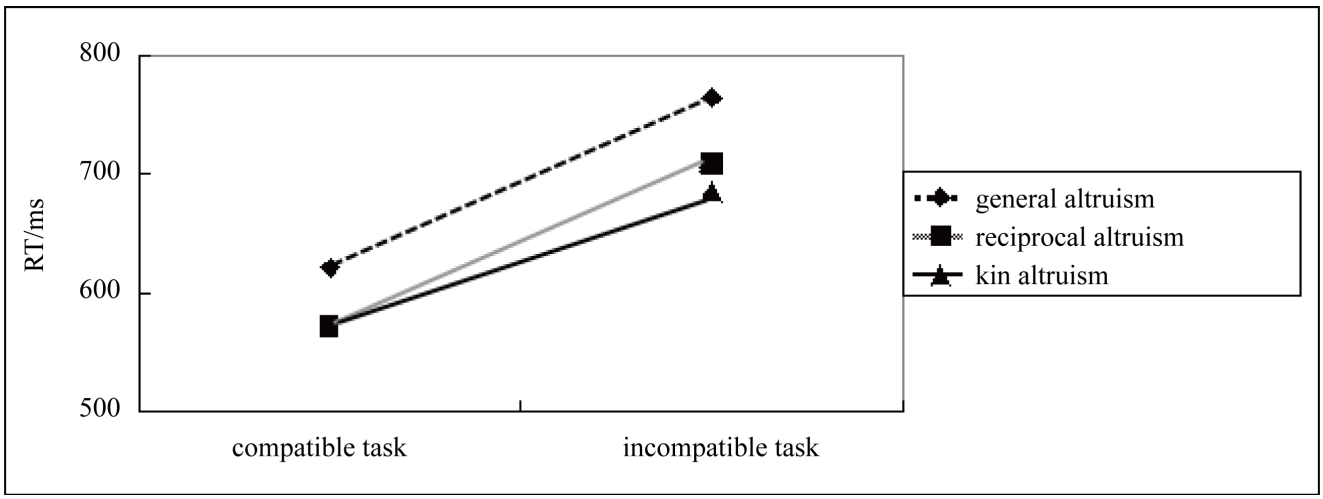

Figure 4. The interaction between altruism type and task type.

the reliability coefficients of the three implicit altruistic self-concept SC-IAT measures range from $0.41-0.79$. These results are mostly consistent with Karpinski \& Steinman (2006), indicating that most of the SC-IAT measures used in the present study were reliable, however, the reliability coefficients of two implicit altruistic self-concept SC-IAT measures(general altruism and kin altruism) were not satisfactory, suggesting the two implicit altruistic self-concept SC-IAT measures should be improved to be used in further research.

We found that the D-values of implicit altruistic self-concept SC-IAT measures are less than those of implicit altruistic attitude SC-IAT, which is consistent with Perugini, Conner, \& O’Gorman (2011). They interpreted this result as a sequential effect because the implicit measures of altruistic self-concepts were administered after the implicit measures of altruistic attitudes.

But in our study, participants who completed the implicit measures of altruistic self-concepts were not the ones who completed the implicit measures of altruistic attitudes, so what Perugini, Conner and O’Gorman proposed is not the case. The truth may be: Chinese participants' implicit attitudes towards altruism were relatively stronger, while their altruistic self-concepts were weak nearly to the point of being neutral. This result needs 
further investigation.

\subsection{Implicit Attitudes towards Three Kinds of Altruism}

Chinese students' implicit attitudes towards general, reciprocal and kin altruism were positive. Their implicit attitudes towards reciprocal and kin altruism were more positive than general altruism, while implicit attitudes towards kin altruism and reciprocal altruism showed no meaningful difference. Therefore hypothesis 1 and hypothesis 2 were partly tested. These results are consistent with the assumption of basic human nature (Hodgson, 2014) and the influence of Chinese culture.

Altruism to kin, to friends and to strangers was advocated by Confucianism (Luo, 2012; Mullis, 2010; Munro, 2002). Confucianism considered genetic relatedness as the criterion of altruism behavior (Nichols, 2013; Mullis, 2010; Wee, 2014; Zwick \& Fletcher, 2014). Reciprocal altruism is also proposed, and reciprocal friendship is of crucial importance in cultivating moral traits (Mullis, 2010). Altruism to strangers is also advocated by Confucians (Wang, Zhang, \& Wang, 2008), but its role is unimportant. When confronting the dilemma of whether his kin or others should be helped a Confucian will choose his kin without hesitation (Mullis, 2010; Munro, 2002).

In the present study the students' implicit attitudes towards kin and reciprocal altruism showed no variance. This can be interpreted by environmental influence. To the students, it is their friends rather than kin who are helpful when dealing with daily affairs, enabling the importance of reciprocal altruism to be elevated to a high level in the students' implicit cognition.

\subsection{Implicit Altruistic Self-Concepts}

Inconsistent with Perugini, Conner, \& O'Gorman (2011), we found no IAT effect in implicit altruistic selfconcept SC-IAT measures. This reveals that, although Chinese students hold positive attitudes towards altruism implicitly, in their implicit self-concepts they are rather neutral (neither altruistic nor selfish). This result contradicts hypothesis 1 , and it may reveal the dark side of Confucianism. This issue should be deeply explored.

\subsection{Honest/Hypocritical Attitudes towards Altruism}

In general, the students regarded kin altruism, reciprocal altruism and general altruism as honest. Though it is more difficult for them to establish implicit association between general altruism and the honest trait, general altruism was not judged as a hypocritical trait. Therefore hypothesis 3 was validated. This is a quite important finding.

\subsection{Difference from Previous Study}

Our study may partly explain Ma’s (1993) results. He found that the altruistic preference of children in Hong Kong and Mainland China decreased in the following direction: helping kin, helping friends, helping strangers, helping enemies, which demonstrated that Chinese have different attitudes towards people who have a different social distance from them. However, we didn't find any obvious difference between implicit attitudes towards kin altruism and reciprocal altruism as revealed by Ma (1993), indicating that the Chinese ethical value has been changing with the times.

The extension of kin altruism to reciprocal and general altruism is a requirement of modern ethics. What is optimistic in the present study is that Chinese students put nearly equal importance on reciprocal altruism and kin altruism, and their implicit attitude towards general altruism is positive. We may predict that traditional Chinese ethics would shift towards a modernizing pathway with the development of internationalization. By that time, China should ascend to a much higher rank in the World Giving Index.

\subsection{Limitation and Future Research Orientation}

The present study has three main limitations. Firstly, only Chinese students participated in this study, and their responses haven't been compared to those of foreign students. Secondly, whether implicit altruism measures can predict altruistic behavior is an unqualified assumption, and this decreases the practical value of the present study. Thirdly, other implicit measures should be employed to cross validate the results of present study. We hope to introduce or develop other IAT measures that are more applicable and valid in Chinese culture. 


\section{Acknowledgements}

We would like to thank Prof. Mitja Back in University of Münster for recommendations of research ideas for this study, as well as project scientist Stephen Harris in Lawrence Berkeley National Lab, Prof. Li Li in Oakland University, and Senior Researcher Meng Jiang in General Motors R\&D for suggestions on improving our language skills and for corrections of grammatical errors prior to submission.

\section{References}

Aspden, T., Ingledew, D. K., \& Parkinson, J. A. (2012). Motives and Health-Related Behaviour: Incremental Prediction by Implicit Motives. Psychology and Health, 27, 51-71. http://dx.doi.org/10.1080/08870446.2010.541911

Banse, R., \& Greenwald, A. G. (2007). Personality and Implicit Social Cognition Research: Past, Present and Future. European Journal of Personality, 21, 371-382. http://dx.doi.org/10.1002/per.638

Bar-Anan, Y., \& Nosek, B. A. (2013). A Comparative Investigation of Seven Indirect Attitude Measures. Behavior Research Methods, 46, 668-688. http://dx.doi.org/10.3758/s13428-013-0410-6

Barclay, P. (2013). Strategies for Cooperation in Biological Markets, Especially for Humans. Evolution and Human Behavior, 34, 164-175. http://dx.doi.org/10.1016/j.evolhumbehav.2013.02.002

Cuyper, K. D., Pieters, G., Claes, L., Vandromme, H., \& Hermans, D. (2013). Indirect Measurement of Perfectionism: Construct and Predictive Validity. Journal of Social and Clinical Psychology, 32, 844-858. http://dx.doi.org/10.1521/jscp.2013.32.8.844

Fiedler, K., Messner, C., \& Bluemke, M. (2006). Unresolved Problems with the "I”, the “A”, and the "T”: A Logical and Psychometric Critique of the Implicit Association Test (IAT). European Review of Social Psychology, 17, 74-147. http://dx.doi.org/10.1080/10463280600681248

Fleischhauer, M., Strobel, A., Enge, S., \& Strobel, A. (2013). Assessing Implicit Cognitive Motivation: Developing and Testing an Implicit Association Test to Measure Need for Cognition. European Journal of Personality, 27, 15-29. http://dx.doi.org/10.1002/per.1841

Fletcher, J. A., \& Zwick, M. (2006). Unifying the Theories of Inclusive Fitness and Reciprocal Altruism. The American Naturalist, 168, 252-262. http://dx.doi.org/10.1086/506529

Gast, A., \& Rothermund, K. (2010). When Old and Frail Is Not the Same: Dissociating Category and Stimulus Effects in Four Implicit Attitude Measurement Methods. Quarterly Journal of Experimental Psychology, 63, 479-498. http://dx.doi.org/10.1080/17470210903049963

Greenwald, A. G., McGhee, D. E., \& Schwartz, J. L. K. (1998). Measuring Individual Differences in Implicit Cognition: The Implicit Association Test. Journal of Personality and Social Psychology, 74, 1464-1480. http://dx.doi.org/10.1037/0022-3514.74.6.1464

Greenwald, A. G., Poehlman, T. A., Uhlmann, E. L., \& Banaji, M. R. (2009). Understanding and Using the Implicit Association Test: III. Meta-Analysis of Predictive Validity. Journal of Personality and Social Psychology, 97, 17-41. http://dx.doi.org/10.1037/a0015575

Hamilton, W. D. (1964). The Genetical Evolution of Social Behavior. Journal of Theoretical Biology, 7, 1-16. http://dx.doi.org/10.1016/0022-5193(64)90038-4

Hodgson, G. M. (2014). The Evolution of Morality and the End of Economic Man. Journal of Evolutionary Economics, 24, 83-106. http://dx.doi.org/10.1007/s00191-013-0306-8

Karpinski, A., \& Hilton, J. L. (2001). Attitudes and the Implicit Association Test. Journal of Personality and Social Psychology, 81, 774-788. http://dx.doi.org/10.1037/0022-3514.81.5.774

Karpinski, A., \& Steinman, R. B. (2006). The Single Category Implicit Association Test as a Measure of Implicit Social Cognition. Journal of Personality and Social Psychology, 91, 16-32. http://dx.doi.org/10.1037/0022-3514.91.1.16

Krupp, D. B., DeBruine, L. M., \& Barclay, P. (2008). A Cue of Kinship Promotes Cooperation for the Public Good. Evolution and Human Behavior, 29, 49-55. http://dx.doi.org/10.1016/j.evolhumbehav.2007.08.002

Lindgren, K. P., Neighbors, C., Teachman, B. A., \& Wiers, R. W. (2013). I Drink Therefore I Am: Validating Alcohol-Related Implicit Association Tests. Psychology of Addictive Behaviors, 27, 1-13. http://dx.doi.org/10.1037/a0027640

Luo, S. R. (2012). Setting the Record Straight: Confucius’ Notion of Ren. Dao, 11, 39-52. http://dx.doi.org/10.1007/s11712-011-9256-8

Ma, H. K. (1993). The Relation of Altruistic Orientation to Human Relationships and Situational Factors in Chinese Children. The Journal of Genetic Psychology, 154, 85-96. http://dx.doi.org/10.1080/00221325.1993.9914724

Mullis, E. C. (2010). Confucius and Aristotle on the Goods of Friendship. Dao, 9, 391-405. 
http://dx.doi.org/10.1007/s11712-010-9185-y

Munro, D. J. (2002). Reciprocal Altruism and the Biological Basis of Ethics in Neo-Confucianism. Dao, 1, 131-141. http://dx.doi.org/10.1007/BF02857092

Nichols, R. (2013). The Origins and Effects of Filial Piety: How Culture Solves an Evolutionary Problem for Parents. Cognition and Culture, 13, 201-230. http://dx.doi.org/10.1163/15685373-12342092

Perugini, M., Conner, M., \& O’Gorman, R. (2011). Automatic Activation of Individual Differences: A Test of the Gatekeeper Model in the Domain of Spontaneous Helping. European Journal of Personality, 25, 465-476. http://dx.doi.org/10.1002/per.826

Popa-Roch, M., \& Delmas, F. (2010). Prejudice Implicit Association Test Effects: The Role of Self-Related Heuristics. Journal of Psychology, 218, 44-50. http://dx.doi.org/10.1027/0044-3409/a000007

Queller, D. C. (1985). Kinship, Reciprocity and Synergism in the Evolution of Social Behaviour. Nature, 318, 366-367. http://dx.doi.org/10.1038/318366a0

Rudolph, A., Schröder-Abé, M., Riketta, M., \& Schütz, A. (2010). Easier When Done Than Said! Implicit Self-Esteem Predicts Observed or Spontaneous Behavior, but Not Self-Reported or Controlled Behavior. Journal of Psychology, 218, 12-19.

Rudolph, A., Schröder-Abé, M., Schütz, A., Gregg, A. P., \& Sedikides, C. (2008). Through a Glass, Less Darkly? Reassessing Convergent and Discriminant Validity in Measures of Implicit Self-Esteem. European Journal of Psychological Assessment, 24, 273-281. http://dx.doi.org/10.1027/1015-5759.24.4.273

Tian, L. L., Liu, W., \& Gilman, R. (2010). Explicit and Implicit School Satisfaction. Social Behavior and Personality, 38, 1345-1354. http://dx.doi.org/10.2224/sbp.2010.38.10.1345

Trivers, R. L. (1971). The Evolution of Reciprocal Altruism. The Quarterly Review of Biology, 46, 35-57. http://dx.doi.org/10.1086/406755

van Ravenzwaaij, D., van der Maas, H. L. J., \& Wagenmakers, E.-J. (2011). Does the Name-Race Implicit Association Test Measure Racial Prejudice? Experimental Psychology, 58, 271-277. http://dx.doi.org/10.1027/1618-3169/a000093

Wang, M. X., Zhang, W., \& Wang, X. L. (2008). The Principle of Family Determination in Organ Donation: The Application of Confucian Ethics. HEC Forum, 20, 183-196. http://dx.doi.org/10.1007/s10730-008-9069-2

Wee, C. (2014). Filial Obligations: A Comparative Study. Dao, 13, 83-97. http://dx.doi.org/10.1007/s11712-013-9359-5

Zwick, M., \& Fletcher, J. A. (2014). Levels of Altruism. Biological Theory, 9, 100-107. http://dx.doi.org/10.1007/s13752-013-0145-8 


\section{Appendix}

\begin{tabular}{cccc}
\hline \multicolumn{2}{|c}{ Appendix A. Word categories in six SC-IAT measures. } & & \\
\hline & Target words & \multicolumn{2}{c|}{ Attribute words } \\
\hline General altruistic attitude SC-IAT & General altruism & Commendatory terms & Derogatory terms \\
Reciprocal altruistic attitude SC-IAT & Reciprocal altruism & Commendatory terms & Derogatory terms \\
Kin altruistic attitude SC-IAT & Kin altruism & Commendatory terms & Derogatory terms \\
General altruistic self-concept SC-IAT & General altruism & Self & Other \\
Reciprocal altruistic self-concept SC-IAT & Reciprocal altruism & Self & Other \\
Kin altruistic self-concept SC-IAT & Kin altruism & Self & Other \\
\hline
\end{tabular}

Appendix B. Target and attribute words and their Chinese counterparts.

\section{General altruistic words}

Charitable (乐善好施), helping those in distress (济危救困), generous (慷慨大方), helpful (乐于助人), support the weak (帮扶弱者), altruism (利他主义)

Reciprocal altruistic words

reciprocate when helped (知恩图报), value feelings and loyalty (重情重义), be adept in finding allies (善结人缘), value friendship (注 重友谊), friendly (待人友好), immersing (相濡以沫)

\section{Kin altruistic words}

family commitment (看重家庭), devoted to offspring (关爱子女), filial piety (孝顺父母), affectionate to sibling (手足情深), respect for family elders (尊敬长辈), loving parents foster dutiful son (父慈子孝)

Commendatory terms (the first five are honest words)

unsophisticated (纯朴), sincere (真挚), real (真实), honest (诚实), concrete (实在), favorite (喜爱), wonderful (美妙), glorious (光荣), pleasant (愉快), smiling (微笑)

Derogatory terms (the first five are hypocritical words) mendacious (虚假), ostentation (卖弄), insincerity (矫饰), affectation (做作), hypocrisy (伪善), distressed (苦恼), terrible (糟糕), sordid (肮脏), wicked (邪恶), harm (伤害)

Neutral words

connecting (承上启下), empty talk (纸上谈兵), turnaround (峰回路转), concentrate (聚精会神)

Self

I (我), me (我), my (我的), we (我们), us (我们), our (我们的)

Other

He (他), his (他的), she (她), her (她的), they (他们), their (他们的)

\section{Scientific Research Publishing}

\section{Submit or recommend next manuscript to SCIRP and we will provide best service for you:}

Accepting pre-submission inquiries through Email, Facebook, Linkedin, Twitter, etc A wide selection of journals (inclusive of 9 subjects, more than 200 journals)

Providing a 24-hour high-quality service

User-friendly online submission system

Fair and swift peer-review system

Efficient typesetting and proofreading procedure

Display of the result of downloads and visits, as well as the number of cited articles

Maximum dissemination of your research work

Submit your manuscript at: http://papersubmission.scirp.org/ 